\title{
Association of Lipid Profile with Body Mass Index in Public Employees in Halabja City, Kurdistan Region of Iraq
}

\author{
Tareq H. Abdullah ${ }^{1}$, Hardi R. Baqi ${ }^{1 *}$, Salar H. Karim², Dashty A. Ghafor ${ }^{2}$ \\ ${ }^{1}$ Department of Medical Laboratory Techniques, Research Center, Halabja Technical Institute, Sulaimani Polytechnic University, Halabja, \\ Kurdistan Region, Iraq, ${ }^{2}$ Department of Laboratories, General Directorate of Health in Halabja, Halabja, Kurdistan Region, Iraq
}

\author{
*Corresponding author: \\ Hardi R. Baqi, Department \\ of Medical Laboratory \\ Techniques, Research \\ Center, Halabja Technical \\ Institute, Sulaimani \\ Polytechnic University, \\ Halabja, Kurdistan Region, \\ Iraq. \\ E-mail: hardi.baqi@spu. \\ edu.iq
}

Received: 16 March 2020

Accepted: 11 May 2020

Published: 30 December 2020

DOI

10.25156/pti.v10n2y2020.pp71-80

\section{A B S T R A C T}

Obesity and overweight are extensive phenomena that reached epidemics extent worldwide, including the Kurdistan region of Iraq. The aim of this study is to evaluate the values of total cholesterol (TC), triglycerides (TG), low-density lipoprotein cholesterol (LDL-C), high-density lipoprotein cholesterol (HDL-C), body mass index (BMI), and the state of physical activity in Halabja's public employees. Overall 355 adults aged from 19 to 63 including 246 males and 109 females contributed to the study. The lipid profiles were tested in all subjects after over-night fasting. In addition, anthropometry measurements were taken; the mean height for males is $1.7129 \mathrm{~m}$ and $1.5732 \mathrm{~m}$ for females. The mean weights of males and females are 80.4813 and $69.9459 \mathrm{~kg}$, respectively. The mean BMI value for males and females is 27.4258 and 28.3274 , respectively. Some of the cases were diagnosed with diabetes, renal diseases, hypertension, and other relevant diseases. 246 of participants adopted sedentary lifestyles while 109 of them lived an active lifestyle. 65, 162, 98, and 206 of participants had TC, TG, LDL-C, and HDL-C off-limits, respectively. Pearson's correlation between BMI with TC, TG, and LDL-C showed a significant relationship at 0.01 level as $0.156^{* *}, 0.140^{* *}$, and $0.144^{* *}$, respectively. $\mathrm{HDL}-\mathrm{C}$ was negatively correlated to $\mathrm{BMI}$ at -0.062 level. The analysis of variance showed statistically significant p-values between TC, TG, and HDL-C according to BMI at $0.027,0.000$, and 0.000 , respectively. The sedentary group of participants showed a higher Mean range of TC, TG, LDL-C, and HDL-C than an active group of participants.

Keywords: Body mass index; High-density lipoprotein cholesterol; Low-density lipoprotein cholesterol; Total cholesterol; Triglycerides

\section{INTRODUCTION}

The essential materials in human body are phospholipids, cholesterol, triglycerides (TG), and fatty acids, which make up the basic structure of cell wall, and act as a starting material to other steroid hormones, bile acids, and Vitamin D (Freitas et al., 2013). TGs made up of a combination of three fatty acids with one glycerol molecule that acts as an energy storage molecule in the body (Alves-bezerra and Cohen, 2018). Lipoproteins cause the lipids to solubilize and be transported in an aqueous solution of the body (Freitas et al., 2013). Plasma lipoproteins are classified into seven groups according to size, apolipoproteins, and lipid composition: (chylomicrons, chylomicron remnants, very low-density lipoprotein (VLDL), IDL, LDL, high-density lipoprotein [HDL], and Lipoprotein-a Lp [a]) (Kenneth and Feingold, 2000). Dyslipidemia is the name signed for any imbalances in the amount of the lipoproteins in the human body. Lipid profile is testing for (total cholesterol [TC], HDL cholesterol [HDL-C], LDL cholesterol [LDL-C], and TG) which is critical for observing the medical state of anyone at risk of heart diseases, atherosclerosis, diabetic mellitus, and other metabolic diseases (Freitas et al., 2013; Brandão et al., 2011). Understanding risk factors for CVD include modifiable factors such as smoking, diabetes, hypertension, high cholesterol, and overweight, which may help to reduce the risk of developing CVD (Bo et al., 2018). Many factors lead to imbalances in the lipid profile levels in the body, including hereditary, lifestyle, and obesity regardless of age (Magnussen et al., 2011). Early measurements of lipid profile are important in preventing the risk of CVD (Freitas et al., 2013), (Brandão et al., 2011). Among major factors leading to (CVD) is hypertension. The presence of hypertension is increased worldwide especially in developing countries (Choudhury et al., 2014; Mora et al., 2013). Common believes are the hypertension is directly related to high levels of lipid profile components other than HDL-C (Mora et al., 2013). Type 2 diabetes mellitus patients are at higher risk of dyslipidemias that causes in developing of heart disease (Alzahrani et al., 
2019; Naqvi et al., 2017). Patients suffer from hepatic diseases susceptible to variations in lipids and lipoproteins in their body (McIntyre, 1978; Muhammed and Jayaraj, 2016). The World Health Organization (WHO) stresses that the not-transmissible chronic diseases (NTCDs) are influenced more in the developed states than the newly developing countries (Brandão et al., 2011). The growth of the NTCDs came as a result of the process of industrialization, economic evolution, urbanism, food globalization of eating practices, sedentary lifestyle, and smoking (Brandão et al., 2011). The benefits of exercise in averting heart disease and other metabolic disorders shown clearly by academic researches that showed regular physical activities cause an increase in HDL-C concentrations and decrease the bad cholesterol and TG (Carreras-González and Ordóñez-Llanosb, 2007; Swain and Franklin, 2006). Changes in amounts of lipid components in the body with an active lifestyle can be comparably smaller and the ratio of the atherogenic index of LDL-C, VLDL-C to the good cholesterol could be smaller as well when regular moderate exercise is chosen as a lifestyle (Carreras-González and Ordóñez-Llanosb, 2007). To achieving health, adults need to be active daily. To be called active, one must collect at least $150 \mathrm{~min}$ of activities per week. These activities include moderate as walking or cycling to intense exercises like (running) (Davies et al., 2019). The major objective of this study is to evaluate the levels of serum (TC, LDL-C, HDL-C, and TG) in public employees in Halabja governorate in Kurdistan region of Iraq. Atherogenic index of plasma value, that calculated by the logarithmic transformation of the resulting number found by dividing plasma TG value to HDL-C value, is a good marker for evaluating risk factor of atherosclerosis and cardiovascular disease (Shen et al., 2016; Dobiášová and Frohlich, 2001). The abundance of small LDL-C and small HDL-C particles in blood is correlated to high coronary artery disease (CAD) risk. Inversely, large HDL-C particles decrease the developing of CAD (Dobiášová and Frohlich, 2001). In the present study, the rate of the lipid profile was evaluated in a group of public employees of Halabja city's population.

\section{MATERIALS AND METHODS}

A cross-sectional research that included Halabja employees in the public sector between 19 and 63 years old from July to August 2019, including 246 males and 109 females were tested for their lipid profile. The study included healthy adults and patients diagnosed with chronic diseases such as (20) diabetic, (30) hypertensive (30), and (16) individuals with renal diseases. Anthropometry measurements used to calculate participants body mass index (BMI). Ethical approvals and informed consent were obtained from each individual participated in the study and they all signed their acceptance for using their data anonymously in our study. The study was conducted after acquiring consent from each government organization that samples were taken from its employees. The medical history of patients was taken from participants individually to confirm any illness from the past and present. Three milliliters of venipuncture blood were collected by sterilized syringes which were poured into gel separator tubes. The collected samples were let to clot then centrifuged at $3800 \mathrm{RPM}$ for $10 \mathrm{~min}$. The clear serum separated in Eppendorf tubes and tested for TC, LDL-C, HDL-C, and TG by Cobas-C111. Anthropometry measurements were taken using (Electronic body scale TCS-200-RT) balance and the BMI calculated and categorized based on the World Health Organization's classification (WHO, 1995). Active and sedentary lifestyles determined by the total minutes of activities per week. These activities include moderate as (walking or cycling) to intense exercises like (running) (Davies et al., 2019).

\section{Statistical Analysis}

The collected data for the study were analyzed using SPSS (IBM SPSS statistics 24). The correlation coefficients between the variables were determined using the Pearson correlation coefficient. Analysis of variance (ANOVA) is used to indicate statically significant differences between the groups; post hoc test is used to show the exact differences among the groups, and t-test for illustrating the effect of some chronic diseases and activities on the lipid profile.

\section{RESULTS}

The collected data from respondents had been recorded, computerized, and quantitatively analyzed directly using statistical analysis methods. The age range of adults included in the study started from 17 to 63 years old, whereas $40.9 \%$ were in their $30 \mathrm{~s}$. The BMI ratio of the participants showed that the majority of the participants in the study were overweight adults; some of them were suffering from obesity. The mean value for BMI of male participants is 27.4258, while females in the study are 28.3274. The total weight of the respondents shows that the minimum weight is $39 \mathrm{~kg}$, the maximum is $130 \mathrm{~kg}$, and the mean value of 355 participant's weight is calculated as $77.2465 \mathrm{~kg}$ with a SD of 14.40839. The total height measurement of the respondents shows the minimum height of the participants to be $1.44 \mathrm{~m}$, the highest one as $1.9 \mathrm{~m}$ with a mean value of $1.67 \mathrm{~m}$, and a SD value of 0.08830 . Among the total of 355 participants, there were 20 patients diagnosed with diabetes, the lipid profile of these patients shows an increase in the mean results of the TC $(175.55 \mathrm{mg} / \mathrm{dL})$ in comparison to non-diabetic $(171.53 \mathrm{mg} / \mathrm{dL})$ individuals. The mean value of TG levels in diabetic patients is $203.8 \mathrm{mg} / \mathrm{dL}$ and is 
higher than those of normal individuals $(164.82 \mathrm{mg} / \mathrm{dL})$. In addition, mean HDL-C and LDL-C results were close in both classes [Table 1]:

Out of 355 subjects, there were 30 patients suffering from episodes of hypertension, the lipid profile of these patients is shown in Table 2:

From 355 cases, there were 16 patients with problems in their kidney; the lipid profile of these patients is shown in Table 3:

In 355 participants, there were 109 persons with an active lifestyle and 246 persons with a sedentary lifestyle; the lipid profile of these persons is shown in Table 4:

Table 1: Lipid profile value in diabetic and non-diabetic individuals

\begin{tabular}{llccc}
\hline Lipid profile $\mathrm{mg} / \mathrm{dL}$ & Groups & $\boldsymbol{n}$ & Mean & SD \\
\hline TC & Non-diabetic & 335 & 171.53 & 34.236 \\
& Diabetic & 20 & 175.55 & 34.104 \\
TG & Non-diabetic & 335 & 164.82 & 102.126 \\
& Diabetic & 20 & 203.80 & 154.677 \\
HDL-C & Non-diabetic & 335 & 40.52 & 9.948 \\
& Diabetic & 20 & 40.00 & 10.716 \\
LDL-C & Non-diabetic & 335 & 106.59 & 27.903 \\
& Diabetic & 20 & 106.75 & 27.659 \\
\hline
\end{tabular}

TC: Total cholesterol, TG: Triglycerides, HDL-C: High-density lipoprotein cholesterol, LDL-C: Low-density lipoprotein cholesterol

Table 2: Lipid profile value in normal and patients with hypertension

\begin{tabular}{llccc}
\hline $\begin{array}{l}\text { Lipid profile test } \\
\text { mg/dL }\end{array}$ & Groups & $\boldsymbol{n}$ & Mean & SD \\
\hline TC & Normal & 325 & 171.99 & 34.548 \\
& Have hypertension & 30 & 169.23 & 30.494 \\
TG & Normal & 325 & 168.96 & 108.070 \\
& Have hypertension & 30 & 146.03 & 76.189 \\
HDL-C & Normal & 325 & 40.31 & 9.994 \\
& Have hypertension & 30 & 42.40 & 9.754 \\
LDL-C & Normal & 325 & 106.72 & 28.022 \\
& Have hypertension & 30 & 105.33 & 26.333 \\
\hline
\end{tabular}

TC: Total cholesterol, TG: Triglycerides, HDL-C: High-density lipoprotein cholesterol, LDL-C: Low-density lipoprotein cholesterol

Table 3: Lipid profile value in normal and patients with renal diseases

\begin{tabular}{llccc}
\hline $\begin{array}{l}\text { Lipid profile test } \\
\mathrm{mg} / \mathrm{dL}\end{array}$ & Groups & $n$ & Mean & SD \\
\hline TC & Normal & 339 & 171.07 & 34.252 \\
& Have renal diseases & 16 & 186.19 & 30.411 \\
TG & Normal & 339 & 167.47 & 105.682 \\
& Have renal diseases & 16 & 157.56 & 112.631 \\
HDL-C & Normal & 339 & 40.16 & 9.721 \\
& Have renal diseases & 16 & 47.50 & 12.853 \\
LDL-C & Normal & 339 & 106.16 & 27.835 \\
& Have renal diseases & 16 & 116.06 & 27.336 \\
\hline
\end{tabular}

TC: Total cholesterol, TG: Triglycerides, HDL-C: High-density lipoprotein cholesterol, LDL-C: Low-density lipoprotein cholesterol
Only 65 participant's TC level is higher than the accepted limit. The TG levels distributions among cases show a normal level for 193 persons and range above $150 \mathrm{mg} / \mathrm{dl}$ of 162 cases. 29 cases had very high TG levels above $300 \mathrm{mg} / \mathrm{dL}$. The majority of participants (206 persons) have their HDL-C below the normal value (40 mg/dL). 149 cases among them have higher than normal values for HDL-C. 98 cases have higher than normal values of LDL-C. Most of participants have LDL-C values between 81 and $120 \mathrm{mg} / \mathrm{dL}$. Pearson's correlation between BMI and lipid profile variables is shown in Table 5. The $P$-value between TC and BMI is $0.156^{* *}$ which is significant at the 0.01 level (two-tailed). The value shows a positive correlation between the two variables.

The crosstab [Table 6] shows the distribution of TC levels among various BMI groups.

Pearson's correlation between BMI and TG is 0.140** [Table 5] which is significant at the 0.01 level (two-tailed). The value shows a positive correlation between the two variables. The distribution of TG levels among various BMI groups is shown in Table 7.

Pearson's correlation between BMI and HDL-C is -0.062 [Table 5] which is non-significant at the 0.01 level (twotailed). The value shows a negative correlation between the two variables. Table 8 shows the distribution of HDL-C levels among various BMI groups.

Pearson's correlation between BMI and LDL-C is 0.144** [Table 5] which is significant at the 0.01 level (two-tailed).

\begin{tabular}{|c|c|c|c|c|}
\hline Lipid profile test mg/DI & Sedentary & $n$ & Mean & SD \\
\hline \multirow[t]{2}{*}{ TC } & Active & 109 & 163.16 & 32.259 \\
\hline & Sedentary & 246 & 175.57 & 34.397 \\
\hline \multirow[t]{2}{*}{$\mathrm{TG}$} & Active & 109 & 163.48 & 99.331 \\
\hline & Sedentary & 246 & 168.59 & 108.782 \\
\hline \multirow[t]{2}{*}{ HDL-C } & Active & 109 & 38.93 & 7.314 \\
\hline & Sedentary & 246 & 41.18 & 10.894 \\
\hline \multirow[t]{2}{*}{ LDL-C } & Active & 109 & 99.67 & 27.282 \\
\hline & Sedentary & 246 & 109.67 & 27.600 \\
\hline
\end{tabular}

TC: Total cholesterol, TG: Triglycerides, HDL-C: High-density lipoprotein cholesterol, LDL-C: Low-density lipoprotein cholesterol

Table 5: Pearson correlation between lipid profile variables and $B M I$ value

\begin{tabular}{lcc} 
Variables $\mathrm{mg} / \mathrm{dL}$ & \multicolumn{2}{c}{ BMI } \\
\cline { 2 - 3 } & Correlation value & $P$-value \\
\hline TC & 0.156 & 0.003 \\
TG & 0.140 & 0.008 \\
HDL-C & -0.062 & 0.247 \\
LDL-C & 0.144 & 0.007 \\
\hline
\end{tabular}

TC: Total cholesterol, TG: Triglycerides, HDL-C: High-density lipoprotein cholesterol, LDL-C: Low-density lipoprotein cholesterol 
The value shows a positive correlation between the two variables. Table 9 shows the distribution of LDL-C levels among various BMI groups.

The relationship between lipid profile variables and BMI is illustrated in Figure 1.

To verify whether the differences are statistically significant or not, ANOVA between groups and within the groups are tested [Table 10] for each (TC, TG, HDL-C, and LDL-C) according to BMI, the overall $P$-value for TC, TG, and HDL-C is equal to 0.027 , 0.000 , and 0.000 , which are smaller than (0.05), that means TC, TG, and HDL-C are statistically different according to BMI, indicating statistically significant difference between BMI groups in term of their TC, TG, and HDL-C. While the p-value for LDL-C equals to 0.091 , which is greater than the statistical significant

Table 6: Distribution of TC $\mathrm{mg} / \mathrm{dL}$ according to BMI values

\begin{tabular}{|c|c|c|c|c|c|c|c|c|}
\hline & \multicolumn{7}{|c|}{$\mathrm{TC} \mathrm{mg} / \mathrm{dL}$} & \multirow[t]{2}{*}{ Tota } \\
\hline & $<81$ & $81-120$ & $121-160$ & $161-200$ & $201-240$ & $241-280$ & $281-320$ & \\
\hline \multicolumn{9}{|l|}{ BMI } \\
\hline$<18.6$ & 0 & 0 & 1 & 3 & 0 & 0 & 0 & 4 \\
\hline $18.6-24.5$ & 1 & 6 & 38 & 30 & 11 & 1 & 0 & 87 \\
\hline $24.5-29.5$ & 1 & 6 & 47 & 71 & 26 & 6 & 1 & 158 \\
\hline $29.5-39.5$ & 0 & 4 & 25 & 50 & 17 & 2 & 0 & 98 \\
\hline$>39.5$ & 0 & 0 & 1 & 6 & 1 & 0 & 0 & 8 \\
\hline Total & 2 & 16 & 112 & 160 & 55 & 9 & 1 & 355 \\
\hline
\end{tabular}

TC: Total cholesterol, BMI: Body mass index

Table 7: Distribution of TG $\mathrm{mg} / \mathrm{dL}$ according to $\mathrm{BMI}$ values

\begin{tabular}{|c|c|c|c|c|c|c|c|c|c|c|c|c|}
\hline & \multicolumn{11}{|c|}{ TG $\mathrm{mg} / \mathrm{dL}$} & \multirow[t]{2}{*}{ Total } \\
\hline & $<51$ & $51-100$ & $101-150$ & $151-200$ & $201-250$ & $251-300$ & $301-350$ & $351-400$ & $401-450$ & $451-500$ & $>500$ & \\
\hline \multicolumn{13}{|l|}{$\mathrm{BMI}$} \\
\hline$<18.6$ & 0 & 1 & 1 & 2 & 0 & 0 & 0 & 0 & 0 & 0 & 0 & 4 \\
\hline $18.6-24.5$ & 2 & 40 & 25 & 11 & 6 & 2 & 0 & 1 & 0 & 0 & 0 & 87 \\
\hline $24.5-29.5$ & 1 & 36 & 40 & 31 & 21 & 12 & 4 & 4 & 1 & 3 & 5 & 158 \\
\hline $29.5-39.5$ & 1 & 18 & 23 & 28 & 9 & 8 & 4 & 3 & 2 & 0 & 2 & 98 \\
\hline$>39.5$ & 0 & 2 & 3 & 3 & 0 & 0 & 0 & 0 & 0 & 0 & 0 & 8 \\
\hline Total & 4 & 97 & 92 & 75 & 36 & 22 & 8 & 8 & 3 & 3 & 7 & 355 \\
\hline
\end{tabular}

TG: Triglycerides, BMI: Body mass index

Table 8: Distribution of HDL-C $\mathrm{mg} / \mathrm{dL}$ according to the BMI values

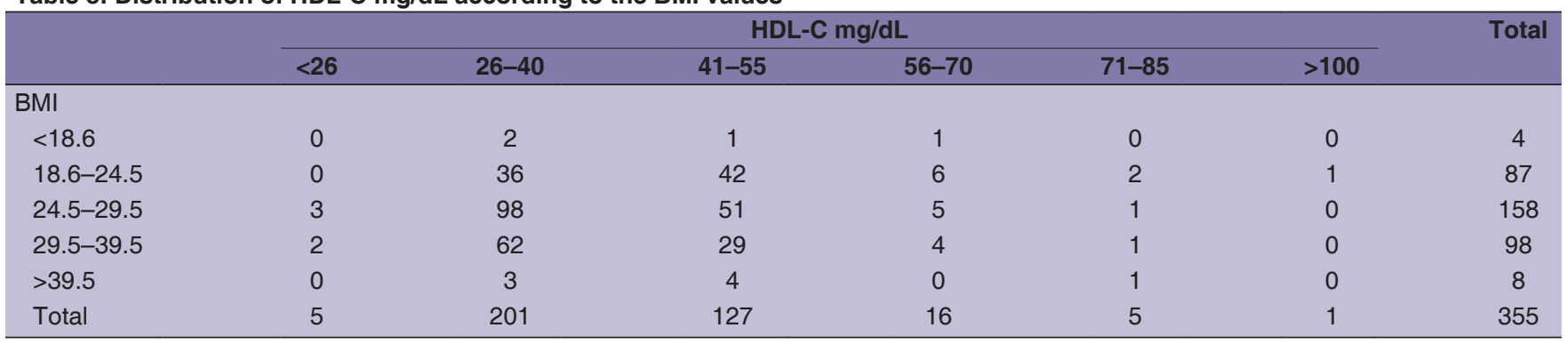

HDL-C: High-density lipoprotein cholesterol, BMI: Body mass index

Table 9: Distribution of LDL-C $\mathrm{mg} / \mathrm{dL}$ according to the BMI values

\begin{tabular}{|c|c|c|c|c|c|c|c|}
\hline & \multicolumn{6}{|c|}{ LDL-C mg/dL } & \multirow[t]{2}{*}{ Total } \\
\hline & $<41$ & $41-80$ & $81-120$ & $121-160$ & $161-200$ & $201-240$ & \\
\hline \multicolumn{8}{|l|}{ BMI } \\
\hline$<18.6$ & 0 & 0 & 4 & 0 & 0 & 0 & 4 \\
\hline $18.6-24.5$ & 1 & 25 & 44 & 13 & 4 & 0 & 87 \\
\hline $24.5-29.5$ & 1 & 21 & 89 & 40 & 6 & 1 & 158 \\
\hline $29.5-39.5$ & 0 & 12 & 55 & 29 & 2 & 0 & 98 \\
\hline$>39.5$ & 0 & 0 & 5 & 3 & 0 & 0 & 8 \\
\hline Total & 2 & 58 & 197 & 85 & 12 & 1 & 355 \\
\hline
\end{tabular}

LDL-C: Low-density lipoprotein cholesterol, BMI: Body mass index 

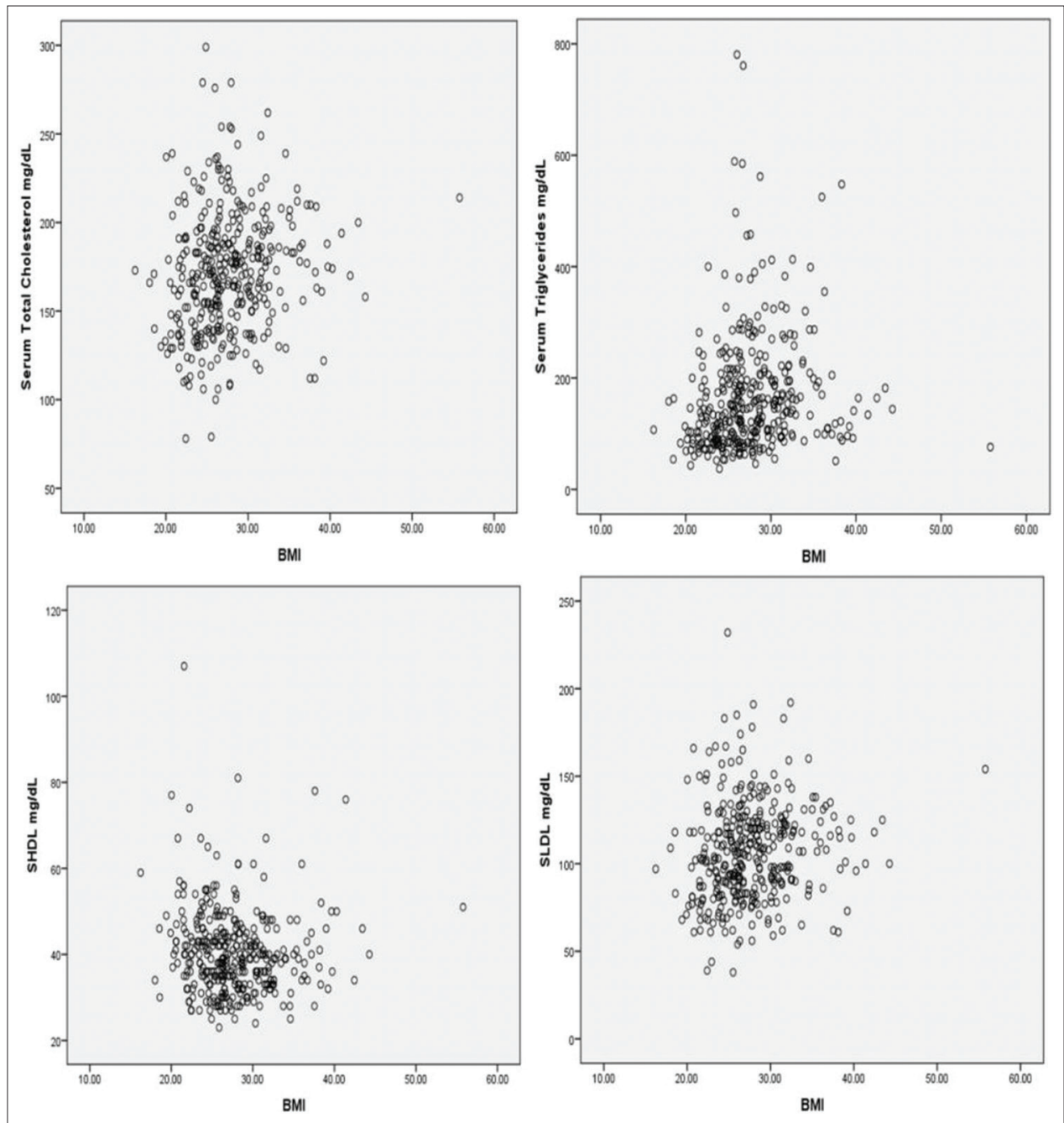

Figure 1: Relationship between TC, TG, HDL-C, and LDL-C with BMI

\begin{tabular}{|c|c|c|c|c|c|}
\hline Variables $\mathrm{mg} / \mathrm{dL}$ & Sum of squares & Df & Mean square & $F$ & Sig. \\
\hline \multicolumn{6}{|l|}{$\mathrm{TC}$} \\
\hline Between Groups & 12730.187 & 4 & 3182.547 & 2.777 & .027 \\
\hline Within Groups & 401167.492 & 350 & 1146.193 & & \\
\hline Total & 413897.679 & 354 & & & \\
\hline \multicolumn{6}{|l|}{ TG } \\
\hline Between Groups & 264019.496 & 4 & 66004.874 & 6.239 & .000 \\
\hline Within Groups & 3702767.366 & 350 & 10579.335 & & \\
\hline Total & 3966786.862 & 354 & & & \\
\hline \multicolumn{6}{|l|}{ HDL-C } \\
\hline Between Groups & 2235.681 & 4 & 558.920 & 5.927 & .000 \\
\hline Within Groups & 33005.035 & 350 & 94.300 & & \\
\hline Total & 35240.715 & 354 & & & \\
\hline \multicolumn{6}{|l|}{ LDL-C } \\
\hline Between Groups & 6199.549 & 4 & 1549.887 & 2.021 & 0.091 \\
\hline Within Groups & 268381.449 & 350 & 766.804 & & \\
\hline Total & 274580.997 & 354 & & & \\
\hline
\end{tabular}

TC: Total cholesterol, TG: Triglycerides, HDL-C: High-density lipoprotein cholesterol, LDL-C: Low-density lipoprotein cholesterol, BMI: Body mass index

level, stating that LDL-C is not statistically significant different according to the BMI.
The results of multiple comparisons between lipid profile variables and BMI groups are shown in Table 11. 
Table 11: Multiple comparison between lipid profile variables and BMI

\begin{tabular}{|c|c|c|c|c|c|c|c|}
\hline \multirow{2}{*}{$\begin{array}{l}\text { Dependent } \\
\text { variable } \mathrm{mg} / \mathrm{dL}\end{array}$} & \multirow{2}{*}{\multicolumn{2}{|c|}{ BMI group comparison }} & \multirow[t]{2}{*}{ Mean difference (I-J) } & \multirow[t]{2}{*}{ SE } & \multirow[t]{2}{*}{ Sig. } & \multicolumn{2}{|c|}{ 95\% Confidence interval } \\
\hline & & & & & & Lower bound & Upper bounc \\
\hline \multirow[t]{2}{*}{$\mathrm{TC}$} & $18.6-24.5$ & $24.5-29.5$ & $-13.112^{*}$ & 4.520 & 0.004 & -22.00 & -4.22 \\
\hline & & $29.5-39.5$ & $-13.095^{\star}$ & 4.987 & 0.009 & -22.90 & -3.29 \\
\hline \multirow[t]{2}{*}{ TG } & $18.6-24.5$ & $24.5-29.5$ & $-62.768^{*}$ & 13.732 & 0.000 & -89.77 & -35.76 \\
\hline & & $29.5-39.5$ & $-59.987^{*}$ & 15.151 & 0.000 & -89.79 & -30.19 \\
\hline \multirow[t]{4}{*}{ HDL-C } & $18.6-24.5$ & $24.5-29.5$ & $5.465^{\star}$ & 1.296 & 0.000 & 2.91 & 8.01 \\
\hline & & $29.5-39.5$ & $4.712^{*}$ & 1.430 & 0.001 & 1.90 & 7.53 \\
\hline & $24.5-29.5$ & $>39.5$ & $-9.179^{*}$ & 3.519 & 0.009 & -16.10 & -2.26 \\
\hline & $29.5-39.5$ & $>39.5$ & $-8.426^{*}$ & 3.571 & 0.019 & -15.45 & -1.40 \\
\hline \multirow[t]{2}{*}{ LDL-C } & $18.6-24.5$ & $24.5-29.5$ & $-8.956^{\star}$ & 3.697 & 0.016 & -16.23 & -1.68 \\
\hline & & $29.5-39.5$ & $-9.137^{*}$ & 4.079 & 0.026 & -17.16 & -1.11 \\
\hline
\end{tabular}

TC: Total cholesterol, TG: Triglycerides, HDL-C: High-density lipoprotein cholesterol, LDL-C: Low-density lipoprotein cholesterol, BMI: Body mass index

The post hoc test in Table 11 shows exactly where the differences among the groups occur by taking asterisks $\left.{ }^{*}\right)$ on it. The asterisk indicating that the two groups being compared are significantly different from one another at $P<0.05$ level. In proportion to the results, BMI group of 18.6-24.5 with each of groups $24.5-29.5$ and $29.5-39.5$ is statistically significantly different from one another according to TC, that is, the BMI group of 18.6-24.5 and 24.5-29.5 differ significantly in terms of their TC with $P$-value $(0.004)$. Furthermore, the BMI group of 18.6-24.5 and 29.5-39.5 differs significantly in terms of their TC with $P=0.009$. Then in the group of TG, the BMI group of 18.6-24.5 with each of groups $24.5-29.5$ and $29.5-39.5$ is statistically significantly different from one another according to TG, that is, the BMI group of 18.6-24.5 and 24.5-29.5 differs significantly in terms of their TG with $P=0.000$. Furthermore, the BMI group of 18.6-24.5 and 29.5-39.5 differs significantly in terms of their TG with $P=0.000$. When in the group of HDL-C, the BMI group of 18.6-24.5 with each of groups 24.5-29.5 and 29.5-39.5 is statistically significantly different from one another according to HDL-C, that is, the BMI group of 18.6-24.5 and 24.5-29.5 differs significantly in terms of their HDL-C with $P=0.000$. Furthermore, the BMI group of 18.6-24.5 and 29.5-39.5 differs significantly in terms of their HDL-C with $P=0.001$, and the BMI group of 24.5-29.5 and $>39.5$ differs significantly in terms of their HDL-C mg/dL with $P=0.009$, so the BMI group of 29.5-39.5 and $>39.5$ differ significantly in terms of their HDL-C $\mathrm{mg} / \mathrm{dL}$ with $P=0.019$. Finally in the group of LDL-C, the BMI group of 18.6-24.5 with each of groups 24.5-29.5 and 29.5-39.5 is statistically significantly different from one another according to LDL-C, that is, the BMI group of 18.6-24.5 and 24.5-29.5 differs significantly in terms of their LDL-C with $P=0.016$. Furthermore, the BMI group of 18.6-24.5 and 29.5-39.5 differs significantly in terms of their LDL-C with $P=0.026$.

Table 12 shows the results of correlation and significance values between lipid profile of non-diabetic and diabetic cases.
Table 12: The relationship between non-diabetic and diabetic cases in terms of their lipid profile values

\begin{tabular}{lcc}
\hline Lipid profile variables, $\mathrm{mg} / \mathrm{dL}$ & Correlation & Sig. \\
\hline TC for non-diabetic and diabetic & 0.289 & 0.217 \\
TG for non-diabetic and diabetic & -0.007 & 0.978 \\
HDL-C for non-diabetic and diabetic & 0.218 & 0.356 \\
LDL-C for non-diabetic and diabetic & 0.099 & 0.679 \\
\hline
\end{tabular}

TC: Total cholesterol, TG: Triglycerides, HDL-C: High-density lipoprotein cholesterol, LDL-C: Low-density lipoprotein cholesterol

From Table 12, the value of correlation and p-value of nondiabetic and diabetic in term of their (TC, TG, HDL-C, and LDL-C) is equals to $0.217,0.978,0.356$, and 0.679 , respectively, and is greater than the significant level (Alpha) that is equal to 0.05 , indicating that there is no relationship between non-diabetic and diabetic in term of their lipid profile in our sample size.

Table 13 shows the t-test for participant's lifestyle (active and sedentary) in term of their TC, TG, HDL-C, and LDL-C, there are differences between the active and sedentary in term of their lipid profile. The result of the test reveals statistically significant differences between the means of the active and sedentary of each TC, and LDL-C at the level of $\alpha=0.05$, from Table 13 , it is noted that the $P$-values for TC, and LDL-C are equal to 0.000 for each them, which are smaller than the level of significant, rejecting the null hypothesis, while there are not a differences between the active and sedentary in terms of their TG and HDL-C. From Table 13, the $P$-values for TG and HDL-C are equal to 0.103 and 0.944 , respectively, which are greater than the significant level, so the null hypothesis cannot be rejected. It says that two means are equal and there are no statistically differences between the means.

Table 14 shows the t-test for participants with normal and hypertension in terms of their TC, TG, HDL-C, and LDL-C. There are differences between the normal and hypertensive cases in their HDL-C and LDL-C. The result of the test reveals statistically significant differences between the means of the normal and hypertensive cases 
Table 13: Results of $t$-test for active and sedentary of TC, TG, HDL-C, and LDL-C

\begin{tabular}{lcccc}
\hline $\begin{array}{l}\text { Lipid profile variables, mg/ } \\
\text { dL }\end{array}$ & $\begin{array}{c}\text { Mean } \\
\text { differences }\end{array}$ & $t$ & Df & Sig. \\
\hline TC for active and sedentary & -17.01835 & -3.710 & 108 & 0.000 \\
TG for active and sedentary & -27.41284 & -1.643 & 108 & 0.103 \\
HDL-C active and sedentary & -.09174 & -0.071 & 108 & 0.944 \\
LDL-C active and sedentary & -14.30275 & -3.761 & 108 & 0.000 \\
\hline
\end{tabular}

TC: Total cholesterol, TG: Triglycerides, HDL-C: High-density lipoprotein cholesterol, LDL-C: Low-density lipoprotein cholesterol

Table 14: Results of $t$-test for the normal and hypertensive cases in terms of their TC, TG, HDL-C, and LDL-C

\begin{tabular}{lcccc}
\hline $\begin{array}{l}\text { Lipid profile } \\
\text { variables, } \mathrm{mg} / \mathrm{dL}\end{array}$ & Mean differences & $t$ & df & Sig. \\
\hline $\begin{array}{l}\text { TC for normal and } \\
\text { hypertension }\end{array}$ & 11.76667 & 1.311 & 29 & 0.200 \\
$\begin{array}{l}\text { TG for normal and } \\
\text { hypertension }\end{array}$ & 34.80000 & 1.298 & 29 & 0.204 \\
$\begin{array}{l}\text { HDL-C for normal and } \\
\text { hypertension } \\
\text { LDL-C normal and }\end{array}$ & -4.53333 & -2.099 & 29 & 0.045 \\
hypertension & 14.16667 & 1.771 & 29 & 0.087 \\
\hline
\end{tabular}

TC: Total cholesterol, TG: Triglycerides, HDL-C: High-density lipoprotein cholesterol, LDL-C: Low-density lipoprotein cholesterol

of each HDL-C at the level of $(\alpha=0.05)$ and LDL-C at the level of $(\alpha=0.10)$. From Table 14, the $P$-values for HDL-C and LDL-C are equal to 0.045 and 0.087 , respectively, which are smaller than the significance level. Hence, the null hypothesis can be rejected. It says that two means are not equal and there are statistically differences between the means, while there are not differences between the normal and hypertensive cases in terms of their TC and TG. From Table 14, $P$-values for TC and TG are equal to 0.200 and 0.204, respectively, which are greater than the significant level. Hence, the null hypothesis cannot be rejected. It says that the two means are equal and there are no statistically differences between the means.

Table 15 compares each of the normal and renal disease cases in terms of their mean scores, mean difference of their scores, and t-test in the groups. The significance of the differences is analyzed using t-test. There is a difference between the normal and renal disease cases in terms of their HDL-C. The result is statistically significant between the means of the two HDL-C at the level of $(\alpha=0.05)$. From [Table 15] the $P$-value for HDL-C is equal to 0.008 which is smaller than the significant level. Hence, the null hypothesis can be rejected. It says that two means are not equal and there is statistically difference between the means. While there are not differences between the normal and renal disease cases in TC, TG, and LDL- $C$ as their $\mathrm{p}$-values equal to $0.455,0.628$, and 0.750 , respectively, which are greater than the significant level. Hence, the null hypothesis cannot be rejected. It says that two means are equal and there are not statistically differences between the means.
Table 15: Results of $t$-test for normal and renal of TC, TG, HDL-C, and LDL-C

\begin{tabular}{lcccc}
\hline Lipid profile variables, mg/DI & $\begin{array}{c}\text { Mean } \\
\text { differences }\end{array}$ & $t$ & df & Sig. \\
\hline $\begin{array}{l}\text { TC for normal and renal } \\
\text { diseases }\end{array}$ & -7.18750 & -0.766 & 15 & 0.455 \\
$\begin{array}{l}\text { TG for normal and renal } \\
\text { diseases }\end{array}$ & 18.81250 & 0.494 & 15 & 0.628 \\
$\begin{array}{l}\text { HDL-C for normal and renal } \\
\text { diseases }\end{array}$ & -10.12500 & -3.028 & 15 & 0.008 \\
$\begin{array}{l}\text { LDL-C normal and renal } \\
\text { diseases }\end{array}$ & 3.06250 & 0.325 & 15 & 0.750 \\
\hline $\begin{array}{l}\text { TC: } \text { Total cholesterol, TG: Triglycerides, HDL-C: High-density lipoprotein } \\
\text { cholesterol, LDL-C: Low-density lipoprotein cholesterol }\end{array}$ & & &
\end{tabular}

\section{DISCUSSION}

This is the first study in Halabja and Kurdistan region of Iraq that shows the actual rates of lipid profile in a sample population in Halabja city public organizations. In the present study, a total number of 355 subjects were measured for their BMI, serum lipid profile and their medical history were investigated. To show the reality of these different groups of individuals, we chose a crosssectional method for sampling that helps in capturing most of the information of the subjected population (Setia, 2016). Height and weight measurements help to determine the risks of high lipid profile; it is proved that maintenance of normal body weight helps to lower the cardiovascular disease risk factor (Addo et al., 2019). The overall activity of individuals per day affects the possibility of getting a lower or higher risk of CVDs. It is proved that every day activities result in the lower risks for CVDs in both middleaged adults and elderly persons as well (Lachman et al., 2018). The correlations between every two variables have been found using this tool in accordance with that reason (Mukaka, 2012). The subjected persons in this study were all adults aged between 18 and 63 years old. This range is the serving age of employees at government organizations before them sent to their retirements at age 63 according to the applied laws in the Kurdistan Regional Government of Iraq (Parlement, 2014). 185 of 355 cases aged from 31 to 45 years old. Only 98 respondents were at ages above 45 while taking the samples. Only 16 of them aged from 18 to 30 . The population used in this study could be considered as an adult population and male-dominant of 246 males to only 109 females. The majority of the population in this study were overweight. 262 persons had their BMI above 24.5 including eight persons suffer from extreme obesity. Females in the study had more mean BMI values than males of $28.3274 \pm 5.80900$ and $27.4258 \pm$ 4.37912, respectively. A high level of BMI is inversely correlated with good cholesterol and is proportional to TG (Shamai et al., 2009). The relationship between diabetes and lipid profile has been intensively studied by researches for decades. The number of patients who suffer from 
diabetes is in a rise according to the WHO data (Purnamasari et al., 2019). From the literature, it has been shown that Type 2 diabetes mellitus causes an increase of the risks to coronary heart disease (CHD) and hyperlipidemias (Nakhjavani et al., 2006). In the present study, 20 diabetic patients were in the sample population. Comparing their lipid profile results with other participants shows that the patients with diabetes have higher mean TC values of $175.55 \mathrm{mg} / \mathrm{dL}$, while $171.53 \mathrm{mg} / \mathrm{dL}$ to other 335 participants. The mean variation of TG is higher in these patients than the normal individuals which are 203.8 and $164.82 \mathrm{mg} / \mathrm{dL}$, respectively. Meanwhile, there is no clear differentiation of the mean values of HDL-C, LDL-C in the two groups in our study. However, these variations are not statistically significant in only 20 diabetic patients of this study. The correlation and p-value of the groups in term of their (TC, TG, HDL-C, and LDL-C) are equal to $0.217,0.978,0.356$, and 0.679 , respectively, which are greater than the significant level (0.05). Blood pressure is proved to be highly effective cause in high levels of lipid profile, that is, because of the atherosclerotic lesions which are rare in low-pressure regions of the circulation, for instance, veins or the pulmonary artery, this happens regardless to the fact that they all exposed to the same amount of lipids and sugar in the body (Kannel, 1987). Although among the subjects in this study, only 30 were diagnosed with episodes of hypertension. The results of the lipid profile were almost the same in TC and LDL-C, with a slight difference in TG and HDL-C. These results were out of expectations as most of the scientific literature assesses that there is a clear relationship between hypertension with high levels of lipid profile. Renal diseases lead to profound hyperlipidemias. This consequence resourced from the deregulations of HDL-C and TG lipoproteins that in turn cause atherosclerosis, cardiovascular diseases, and sometimes cause mortality in chronic renal failure patients. Hence, controlling higher levels of lipid profile in these patients decreases the fatal risk of chronic kidney disease (Kumari and Srinivas, 2018). Only 16 persons out of 355 have experienced kidney problems including kidney stones, inflammations, urine crystals, and chronic renal failure at the time of the study. The lipid profile test, however, indicated different results in the two groups. Mean TC and LDL-C levels in 16 individuals with renal diseases are higher than other 339 normal persons. While the HDL-C, and TG results were quite different. Engaging in an active lifestyle is increasingly associated with higher levels of favored HDL-C and lower levels with TG, TC, and LDL-C (Crichton and Alkerwi, 2015). Individuals with a sedentary lifestyle almost have higher BMI, faced with risks of hypertension and have the worse profile of lipids in their body in which leads to risks of affecting cardiovascular diseases (León-Latre et al., 2014).
Only $30.7 \%$ of 355 participants in the study had a daily active lifestyle. The results of TC, TG, HDL-C, and LDL-C among those with this healthy habit show clear indication on the effectiveness of daily sports on lipid profile. To compare the mean results, we can see that TC is 163.16, 175.57, TG is $163.48,168.59$, HDL-C is $38.93,41.18$, and LDL-C is $99.67,109.67$ for both active and sedentary groups, respectively. The population in the study is divided according to their lipid profile ranges. The TC level starting from $<81 \mathrm{mg} / \mathrm{dL}$ was only observed in two persons out of 355. Others 288 people had normal TC levels below $200 \mathrm{mg} / \mathrm{dL}$. The other 65 persons were above reference ranges $>200 \mathrm{mg} / \mathrm{dL}$. The majority of the participants in the study were healthy individuals in terms of TC as in the literature the reference range of TC is calculated to be below $200 \mathrm{mg} / \mathrm{dL}$ (Jalali et al., 2013). Serum TG in the population starting from $<51 \mathrm{mg} / \mathrm{dL}$ is seen in 4 persons. 189 cases had their TG levels $<150 \mathrm{mg} / \mathrm{dL}$. Other 162 out of 355 cases have their TG's above the reference value including 7 with very high values above $500 \mathrm{mg} / \mathrm{dL}$. The clinical practice guideline literature recommends that only fasting levels of TG be considered in the diagnosis of hypertriglyceridemia. The ranges below $150 \mathrm{mg} / \mathrm{dL}$ are considered normal while (150-999 mg/dL) called as mild and moderate values of TG. The levels above $1000 \mathrm{mg} / \mathrm{dL}$ are considered as severe and very severe hypertriglyceridemia (Berglund et al., 2012). The HDL-C level below $40 \mathrm{mg} / \mathrm{dL}$ is repeated in 206 persons out of 355 participants. The ranges below $40 \mathrm{mg} / \mathrm{dL}$ are accounted for abnormal values in most of the literature (Malati and Mahesh, 2009). Other 149 persons have normal values above the lower limit including only 1 above $100 \mathrm{mg} / \mathrm{dL}$. Diet is of great importance to the levels of HDL-C in the blood that can alter the range of it. There is enormous interest in increasing the HDL-C levels that come from its protective role in coronary heart diseases (Brinton et al., 1990). Most of the encounters in this study (257) have their LDL-C levels below $120 \mathrm{mg} / \mathrm{dL} .98$ persons have abnormally high levels of bad cholesterol up to $240 \mathrm{mg} / \mathrm{dL}$. People with high LDL-C above $190 \mathrm{mg} / \mathrm{dL}$ and low HDL-C below $40 \mathrm{mg} / \mathrm{dL}$ face greater risk of getting atherosclerosis, whereas those below $100 \mathrm{mg} / \mathrm{dL}$ for LDL-C and above $40 \mathrm{mg} / \mathrm{dL}$ for HDL-C face lesser risks of getting it (Hao and Friedman, 2014). Atherosclerosis and plaque formation within blood vessels and arteries start with a lesion on the endothelial layer of them that let LDL-C to be transferred into the intima, then converting into oxidized LDL-C cholesterol by the actions of free radicals which are able of oxidizing LDL-C (Gui et al., 2012; Hao and Friedman, 2014). The correlation between BMI and TC proved to be a linear positive correlation throughout the literature (Nwaiwu and Ibe, 2015). In this study, the Pearson's correlation value of these two variables is $0.156^{* *}$ which 
denotes a significant relationship between them at 0.01 level (two-tailed). This value suggests that by increasing the mean BMI value of the sample population, the average TC increases as well and vice versa. The correlation between BMI with TG and LDL-C is also a significant positive value at rates of $0.140^{* *}$ and $0.144^{* *}$ at the 0.01 level (two-tailed), respectively. However, Pearson's correlation value shows a negative correlation between BMI and HDL-C value. The value is -0.062 that is not significant at the 0.01 level (twotailed). This means in higher levels of HDL-C, BMI is lower, so there is a reverse correlation between these two variables. Slim body weight is very dependent on the amount of HDL-C in the body. There is an inverse relationship between BMI and the concentration of HDL-C (Park et al., 2018).

\section{CONCLUSION}

The present study is the first of its kind to be conducted specifically in government employees in Halabja and Kurdistan region of Iraq. It is of great importance to evaluate the health status of these groups of public servants. The results came out of this study show that the overall health status of the subjected individuals in terms of their lipid profile test is good. However, in terms of individuals activities and BMI values, there are abnormalities as most of the employees' adopt a sedentary lifestyle on the daily basis that causes them to face higher risks of getting hyperlipidemias complications. Anthropometry measurements of the females in the study indicate that they are mostly adopting sedentary lifestyle and have higher BMI values than males in the study. It is crucial to point out the fact that most cases in the study have low levels than normal of HDL-C and higher levels than normal of LDL-C in their blood. Diet along with engaging in an active lifestyle can play a major role in regulating these abnormalities in person lipid profiles.

\section{REFERENCES}

Addo, S. A., F. zVuvor, M. Steiner, C. Nti and J. Adjimani. 2019. Impact of successful weight loss maintenance on serum lipids and glucose concentrations of previous participants of a weight loss programme in accra, Ghana. J. Nutr. Metab. 10113: 1-12.

Alves-bezerra, M. and D. E. Cohen. 2018. Triglyceride metabolism in the liver. Compr. Physiol. 8(1): 1-8.

Alzahrani, S. H., M. Baig, M. M. Aashi, F. K. Al-shaibi, D. A. Alqarni and W. H. Bakhamees. 2019. Association between glycated hemoglobin $(\mathrm{HbA} 1 \mathrm{c})$ and the lipid profile in patients with Type 2 diabetes mellitus at a tertiary care hospital: A retrospective study. Diabetes Metab. Syndr. Obes. 12: 1639-1644.

Berglund, L., J. D. Brunzell, A. C. Goldberg, I. J. Goldberg, F. Sacks, M. H. Murad and A. F. H. Stalenhoef. 2012. Evaluation and treatment of hypertriglyceridemia: An endocrine society clinical practice guideline. J. Clin. Endocrinol. Metab. 97(9): 2969-2989.
Bo, M. S., W. L. Cheah, S. Lwin, T. M. New, T. T. Win and M. Aung. 2018. Understanding the relationship between atherogenic index of plasma and cardiovascular disease risk factors among staff of an university in Malaysia. J. Nutr. Metab. 2018: 7027624.

Brandão, M. P., F. L. Pimentel and M. F. Cardoso. 2011. Impact of academic exposure on health status of university students. Rev. Saude Publica. 45(1): 49-58.

Brinton, E. A., S. Eisenberg and J. L. Breslow. 1990. A Low-fat diet decreases high density lipoprotein (HDL) cholesterol levels by decreasing HDL apolipoprotein transport rates. J. Clin. Invest. 85(1): 144-151.

Carreras-González, G. and J. Ordóñez-Llanosb. 2007. Adolescence, physical activity, and metabolic cardiovascular. Rev. Esp. Cardiol. 60(6): 565-568.

Choudhury, K. N., A. K. M. Mainuddin, M. Wahiduzzaman and I. S. Mohammed. 2014. Serum lipid profile and its association with hypertension in Bangladesh. Vasc. Health Risk Manag. 10: 327-332.

Crichton, G. E. and A. Alkerwi. 2015. Physical activity, sedentary behavior time and lipid levels in the observation of cardiovascular risk factors in luxembourg study. Lipids Health Dis. 14(1): 1-9.

Davies, D. S. C., F. Atherton, M. McBride and C. Calderwood. 2019. UK Chief Medical Officers Physical Activity Guidelines. Department of Health and Social Care, UK, September. p1-65. Available from: https://www.gov.uk/government/publications/ physical-activity-guidelines-uk-chief-medical-officers-report.

De Freitas, R. W. J., M. F. M. Araújo, A. C. S. Lima, D. C. R. Pereira, A. M. P. Alencar and M. M. C. Damasceno. 2013. Study of lipid profile in a population of university students. Rev. Lat. Am. Enfermagem. 21(5): 1151-1158.

Dobiášová, M. and J. Frohlich. 2001. The plasma parameter log (TG/ $\mathrm{HDL}-\mathrm{C})$ as an atherogenic index: Correlation with lipoprotein particle size and esterification rate inapob-lipoprotein-depleted plasma (FERHDL). Clin. Biochem. 34(7): 583-588.

Feingold, K. R., C. Grunfeld, B. Anawalt, A. Boyce, G. Chrousos, W. W. de Herder, K. Dungan, A. Grossman, J. M. Hershman, H. J. Hofland, G. Kaltsas, C. Koch, P. Kopp, M. Korbonits, R. McLachlan, J. E. Morley, M. New, J. Purnell, F. Singer, C. A. Stratakis, D. L. Trence and D. P. Wilson. 2000. Introduction to lipids and lipoproteins. In: Endotext. MDText. Com, Inc., South Dartmouth, MA. p2000-2018.

Gui, T., A. Shimokado, Y. Sun, T. Akasaka and Y. Muragaki. 2012. Diverse roles of macrophages in atherosclerosis: From inflammatory biology to biomarker discovery. Mediators Inflamm. 2012: 693083.

Hao, W. and A. Friedman. 2014. The LDL-HDL profile determines the risk of atherosclerosis: A mathematical model. PLoS One. 9(3): e90497.

Jalali, M. T., A. M. Honomaror, A. Rekabi and M. Latifi. 2013. Reference ranges for serum total cholesterol, HDL-cholesterol, LDLcholesterol, and VLDL-cholesterol and triglycerides in healthy iranian ahvaz population. Indian J. Clin. Biochem. 28(3): 277-282.

Kannel, W. B. 1987. Hypertension and other risk factors in coronary heart disease. Am. Heart J. 114(4 PART 2): 918-925.

Kumari, K. R. and B. Srinivas. 2018. Study of lipid profile in patients with chronic kidney disease on conservative management and hemodialysis. Int. J. Sci. Stud. 6(7): 22.

Lachman, S., S. M. Boekholdt, R. N. Luben, S. J. Sharp, S. Brage, K. T. Khaw, R. J. Peters and N. J. Wareham. 2018. Impact of physical activity on the risk of cardiovascular disease in middleaged and older adults: EPIC Norfolk prospective population study. Eur. J. Prev. Cardiol. 25(2): 200-208. 
León-Latre, M., B. Moreno-Franco, E. M. Andrés-Esteban, M. Ledesma, M. Laclaustra, V. Alcalde, J. L. Peñalvo, J. M. Ordovás, J. A. Casasnovas and Aragon Workers' Health Study investigators. 2014. Sedentary lifestyle and its relation to cardiovascular risk factors, insulin resistance and inflammatory profile. Rev. Esp. Cardiol. (Engl Ed). 67(6): 449-455.

Magnussen, C. G., R. Thomson, V. J. Cleland, O. C. Ukoumunne, T. Dwyer and A. Venn. 2011. Factors affecting the stability of blood lipid and lipoprotein levels from youth to adulthood. Arch. Pediatr. Adolesc. Med. 165(1): 68-76.

Malati, T. and M. R. U. Mahesh. 2009. Reference intervals for serum total cholesterol, HDL-cholesterol, LDL-cholesterol, triglycerides, Lp (a), apolipoprotein A-I, A-II, B, C-II, C-III, and E in healthy South Indians from Andhra Pradesh. Indian J. Clin. Biochem. 24(4): 343-355

Mclntyre, N. 1978. Plasma lipids and lipoproteins in liver disease. Gut. 19: 526-530.

Mora, S., R. J. Glynn and P. M. Ridker. 2013. High-density lipoprotein cholesterol, size, particle number, and residual vascular risk after potent statin therapy. Circulation. 128: 1189-1197.

Muhammed, H. P. and K. Jayaraj. 2016. Correlation of lipid profile in patients with severity of liver disease: A cross sectional study in a tertiary care hospital. Int. J. Res. Med. Sci. 5: 326.

Mukaka, M. M. 2012. Statistics corner: A guide to appropriate use of correlation coefficient in medical research. Malawi Med. J. 24(3): 69-71.

Nakhjavani, M., A. Esteghamati, F. Esfahanian and A. R. Heshmat. 2006. Dyslipidemia in Type 2 diabetes mellitus: More atherogenic lipid profile in women. Acta Med. Iran. 44(2): 111-118.

Naqvi, S., S. Naveed, Z. Ali, S. M. Ahmad, R. Asadullah Khan, H. Raj, S. Shariff, C. Rupareliya, F. Zahra and S. Khan. 2017. Correlation between glycated hemoglobin and triglyceride level in Type 2 diabetes mellitus. Cureus. 9: e1347.
Nwaiwu, O. and B. C. Ibe. 2015. Relationship between serum cholesterol and body mass index in Nigeria schoolchildren aged 2-15 years. J. Trop. Pediatr. 61(2): 126-130.

Park, K. H., D. Yadav, S. J. Kim, J. R. Kim and K. H. Cho. 2018. Slim body weight is highly associated with enhanced lipoprotein functionality, higher HDL-C, and large HDL particle size in young women. Front. Endocrinol. (Lausanne). 9: 406.

Parlement, I. 2014. Law No. 9 of 2014 on Unified Retirement Law. Available from: http://www.lo.org/dyn/natlex/natlex4.detail?p_ lang $=e n \& p \_$isn $=100291 \& p \_c o u n t r y=\mid R Q \& p \_c o u n t=235 \quad$ [Last accessed on 2019 Dec 29].

Purnamasari, D., R. Aulia, M. S. Abdaly and A. Hazim. 2019. Hypercholesterolemia as the first manifestation of metabolic abnormalities in normoglycemic young adult male with family history of Type 2 diabetes mellitus. Diabetes Metab. Syndr. 13(2): 969-974.

Setia, M. S. 2016. Methodology series module 3: Cross-sectional studies. Indian J. Dermatol. 61(3): 261-264.

Shamai, L. E. Lurix, M. Shen, G. M. Novaro, S. Szomstein, R. Rosenthal, A. V. Hernandez and C. R. Asher. 2011. Association of body mass index and lipid profiles: Evaluation of a broad spectrum of body mass index patients including the morbidly obese. Obes. Surg. 21(1): 42-47.

Shen, S., Y. Lu, H. Qi, F. Li, Z. Shen, L. Wu, C. Yang, L. Wang, K. Shui, Y. Wang, D. Qiang, J. Yun and X. Weng. 2016. Association between ideal cardiovascular health and the atherogenic index of plasma. Medicine (Baltimore). 95(24): e3866.

Swain, D. P. and Franklin, B. A. 2006. Comparison of cardioprotective benefits of vigorous versus moderate intensity aerobic exercise. Am. J. Cardiol. 97(1): 141-147.

World Health Organization. 1995. Physical Status: The Use and Interpretation of Anthropometry. World Health Organization, Geneva. p1-463. 